\title{
MASS TRANSFER STUDIES IN AN AGITATED VESSEL WITH RADIAL-AXIAL IMPELLER COMBINATION
}

\author{
Shwetha Karanth ${ }^{1}$, B.S.Thirumalesh ${ }^{2}$ \\ ${ }^{1}$ Department of Chemical Engineering, Dayananda Sagar College of Engineering, Bangalore, India \\ ${ }^{2}$ Department of Chemical Engineering, Dayananda Sagar College of Engineering, Bangalore, India
}

\begin{abstract}
The effect of radial-axial impeller combination in dual configuration was tested for gas liquid mass transfer coefficient $\left(K_{L} a\right)$ and compared with that of dual axial impeller $\left(30^{\circ}\right.$ Pitched blade) combination. The trials were conducted at gas rates of 2litre/min to 10litre/min and agitation rates of 180rpm to 360rpm.Good mass transfer coefficient was obtained by replacing the lower axial impeller with a radial impeller. Rushton Turbine and Curved blade (half pipe) impeller were used in replacing the lower axial impeller. Amongst the two radial impellers, curved blade resulted in higher $K_{L} a$ than Rushton Turbine at highest gassing rate tested. About 15-35\% and 20-48\% increase in $K_{L} a$ was observed by replacing lower pitched blade impeller with Rushton and Curved blade impeller each. The results from the present study shows the capability of replacing lower axial impeller with Radial impeller and retrofitting existing lower Rushton Turbine with Curved blade impeller.
\end{abstract}

Keywords: Mass transfer coefficient, Rushton, Axial, agitated vessel. $* * *$

\section{INTRODUCTION}

Many Chemical and Biochemical processes require oxygen and they employ agitators to achieve the goal of mass transfer. Oxygen being sparingly soluble in water requires impellers to induce smaller bubbles and improve the dissolution. This oxygen transfer or dissolution depends on various process parameters. Mass transfer in a gas liquid system depends on properties of the fluid (media, salt solutions), impeller type, the geometry of the system, agitation speed, and the flowrate of air. Few of the literature states that sparger geometry and air flowrate has less effect on mass transfer.

The oxygen transfer rate in a well mixed system is given as

$$
\mathrm{dC} / \mathrm{dt}=\mathrm{OTR}=\mathrm{K}_{\mathrm{L}} \mathrm{a}\left(\mathrm{C}^{*}-\mathrm{C}_{\mathrm{L}}\right)
$$

Where

$\mathrm{C}^{*}$ is the equilibrium oxygen concentration to be calculated by Henry's law

$\mathrm{C}_{\mathrm{L}}$ is the actual oxygen concentration in liquid at any given time

$\mathrm{K}_{\mathrm{L}}$ is the liquid phase resistance

$\mathrm{a}$ is the gas liquid interfacial area

Radial flow turbines are known to be good gas liquid dispersers. They impart high shear causing the bubbles that reach the impeller blades to break and increase oxygen transfer to the liquid. Standard Flat blade turbine also called Rushton turbine is a top choice in Industries for all the two phase dispersion processes. The classical Rushton turbine has a high power number of 5.5-6. This contributes to the power requirement of the agitated vessel and also the power imparted to the mixing liquid. Besides this Rushton turbine turns out to be a poor gas handler at high aeration rates, they experience significant power drop upon gassing which influences the mass transfer. Disk turbines with curved blades are extensively studied $[1,8,9]$.They are found to be better gas handlers and experience lesser loss in power upon aeration. This blade shape also contributes to lesser cavity formation behind the blades and hence improves the mass transfer capabilities. Axial Impellers are known to impart fewer shears. They also have lower power number and hence require less power. They dissipate less power into liquid and hence lesser utility requirement for heat removal.

Combination of Radial-Axial Impeller is being studied by various researchers. Varied observations with some claiming the combination to be better than dual Rushton and some claiming poor performance in terms of mass transfer can be seen in literature. However the efficiency of the combination depends on the type of axial and radial impeller used. Andrew and Theodore [4] compared $\mathrm{K}_{\mathrm{L}} \mathrm{a}$ obtained from eleven different Impeller combinations. They observed that dual impeller configuration with upper axial impeller gives higher $\mathrm{K}_{\mathrm{L}} \mathrm{a}$ values and that at high aeration rates lower concave/curved blade gave $\mathrm{K}_{\mathrm{L}} \mathrm{a}$ similar to those of the Rushton-axial dual impeller schemes. But they preferred using lower concave blade owing to its improved mass transfer performance. Puthli et al [5] assessed the combination of radial-axial impeller combination in dual and triple impeller configuration and found the best results in terms of $\mathrm{K}_{\mathrm{L}} \mathrm{a}$ were obtained in triple impeller combination with one lower Rushton impeller and two upper pitched blade impeller. Arjunwadkar et al [7] also performed similar experiments and found good gas hold; gas-liquid mass transfer coefficient using the least power could be achieved with combination of lower disc turbine- upper pitched blade downflow impeller. 
The present study aims at evaluating the $\mathrm{K}_{\mathrm{L}}$ a for dual Pitched blade, Rushton Turbine -Pitched blade combination, curved blade-Pitched blade combination at various process parameters.

\section{METHODOLOGY}

\subsection{Vessel Configuration}

All the experiments were conducted in a cylindrical vessel with ellipsoidal bottom. The internal diameter $(\mathrm{T})$ of the vessel was $268 \mathrm{~mm}$ and height $540 \mathrm{~mm}(\mathrm{H})$. Four removable baffles of $\mathrm{T} / 10$ width were placed at right angles to each other. Rushton Turbine, Curved blade (half pipe) Impeller and $30^{\circ}$ Pitched blade Impeller (down pumping) of $\mathrm{D} / \mathrm{T}$ ratio $0.4,0.43$ and 0.5 each were employed in agitation. Ring sparger with diameter of $0.8 \mathrm{D}$ with 8holes of $2 \mathrm{~mm}$ diameter was used. Impellers were used with a clearance of 1.5D from each other $\left(\mathrm{C}_{1}\right)$ and clearance of $\mathrm{D}$ from bottom $\left(\mathrm{C}_{2}\right)$. Dissolved oxygen was measured using a polarographic probe. The experiments were performed at $37 \pm 2^{\circ} \mathrm{C}$ and without any back pressure. The measurements were done in triplicates to check the reproducibility. A reproducibility of $15-20 \%$ was observed. Fig 1 gives the schematic representation and geometrical parameters of the vessel.

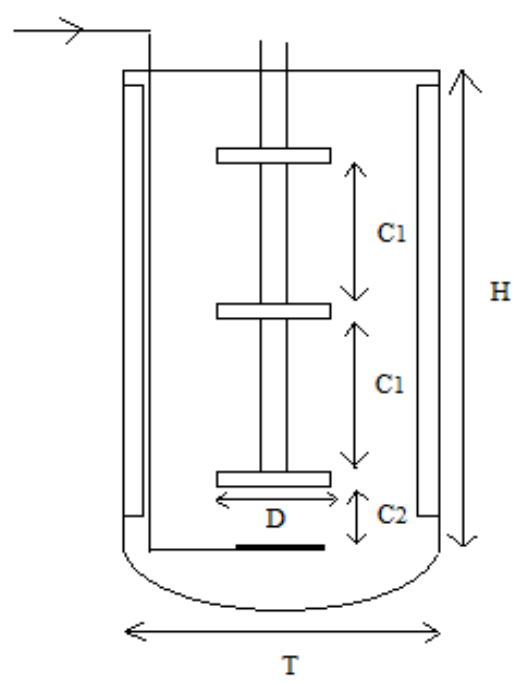

Fig-1: Geometrical Parameters of the vessel

\subsection{Determination of $\mathrm{K}_{\mathrm{L}} \mathrm{a}$}

$\mathrm{K}_{\mathrm{L}}$ a was determined using static gassing out method. Nitrogen was introduced to bring the DO level to less than $1 \%$ following which compressed air was introduced to reach a saturated DO level. A plot of $\ln \left(\mathrm{C}^{*}-\mathrm{C}_{\mathrm{L}}\right)$ versus time was drawn for each trial. $\mathrm{K}_{\mathrm{L}}$ a was obtained from the slope of this plot. The $\mathrm{K}_{\mathrm{L}} \mathrm{a}$ was determined at 2lpm, 51pm, 101pm air flowrates and 180rpm, 270rpm, 360rpm agitation rates. The test solutions used were deionised water, $1 \%$ Sodium Chloride, $0.6 \%$ dextrose. The concentrations of test solutions and the agitation and aeration rates are similar to the one used in fermentation and cell culture processes.

\section{RESULTS AND DISCUSSION}

\subsection{Effect of Impeller Rotation Speed on $K_{L} a$}

Impeller speed is one of the important factors that effects gas liquid mass transfer in an agitated vessel. Fig 2 shows the effect of agitation rate on $\mathrm{K}_{\mathrm{L}} \mathrm{a}$. The $\mathrm{K}_{\mathrm{L}} \mathrm{a}$ values were found to increase with increasing impeller speed. The increase in $\mathrm{K}_{\mathrm{L}}$ a values is due to the breakage of rising bubbles by the impeller blade giving rise to more interfacial area for gas transfer. At $10 \mathrm{lpm}$ all three Impeller combinations show a linear increase in $\mathrm{K}_{\mathrm{L}}$ a values with the increasing agitation. Both $1 \mathrm{r} 1 \mathrm{p}$ and $1 \mathrm{c} 1 \mathrm{p}$ combination yield better mass transfer coefficient values than $2 \mathrm{p} .1 \mathrm{c} 1 \mathrm{p}$ and $1 \mathrm{r} 1 \mathrm{p}$ gave similar $\mathrm{K}_{\mathrm{L}}$ a values at all tested impeller speeds. The lower radial impeller diffuses the gas emerging from the sparger and allows an upward movement of the bubbles. This is a better option than lower down pumping pitched blade impeller.

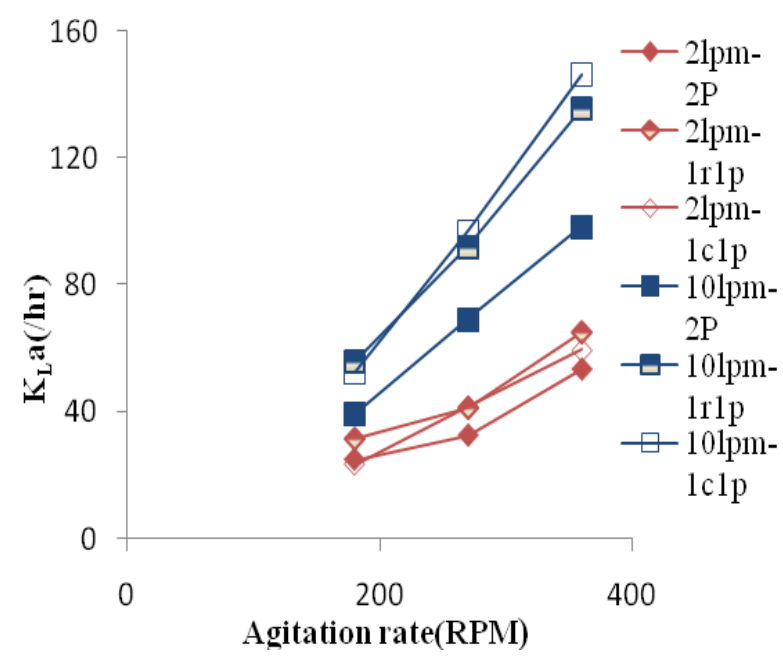

Fig-2: Effect of agitation rate on $\mathrm{K}_{\mathrm{L}} \mathrm{a}$ for different Impeller combinations

\subsection{Effect of Gas Flow Rate on $\mathrm{K}_{\mathrm{L}} \mathrm{a}$}

Fig 3 shows the effect of aeration rate on $\mathrm{K}_{\mathrm{L}} \mathrm{a}$. Increasing the aeration rate increased the $\mathrm{K}_{\mathrm{L}} \mathrm{a}$ values. At a constant agitation rate of $180 \mathrm{rpm} 1 \mathrm{r} 1 \mathrm{p}$ combination showed better mass transfer coefficient than $2 \mathrm{P}$ and also at the lowest gas flowrate of $21 \mathrm{pm}, 1 \mathrm{r} 1 \mathrm{p}$ showed higher performance than $2 \mathrm{P}$ and $1 \mathrm{c} 1 \mathrm{p}$ combination. However at higher agitation rate of $360 \mathrm{rpm}$ both $1 \mathrm{c} 1 \mathrm{p}$ and $1 \mathrm{r} 1 \mathrm{p}$ yielded significantly higher $\mathrm{K}_{\mathrm{L}} \mathrm{a}$ values than $2 \mathrm{P}$. Two different trends of smaller increase of $\mathrm{K}_{\mathrm{L}}$ a from $21 \mathrm{pm}$ to $5 \mathrm{lpm}$ and greater increase from5lpm to $101 \mathrm{pm}$ at $180 \mathrm{rpm}$ was observed. But at $360 \mathrm{rpm}$ the two different trend did not exist. Higher gas flowrates accompanied by high speeds help in breaking bubbles thus increasing mass transfer. As the gas flow rate is increased $1 \mathrm{c} 1 \mathrm{p}$ combination is better performer than $1 \mathrm{r} 1 \mathrm{p}$. This shows the poor gas handling capabilities of Rushton Turbine. Also Curved blade has lower power requirements at high gas flowrates compared to Rushton turbine [3]. 


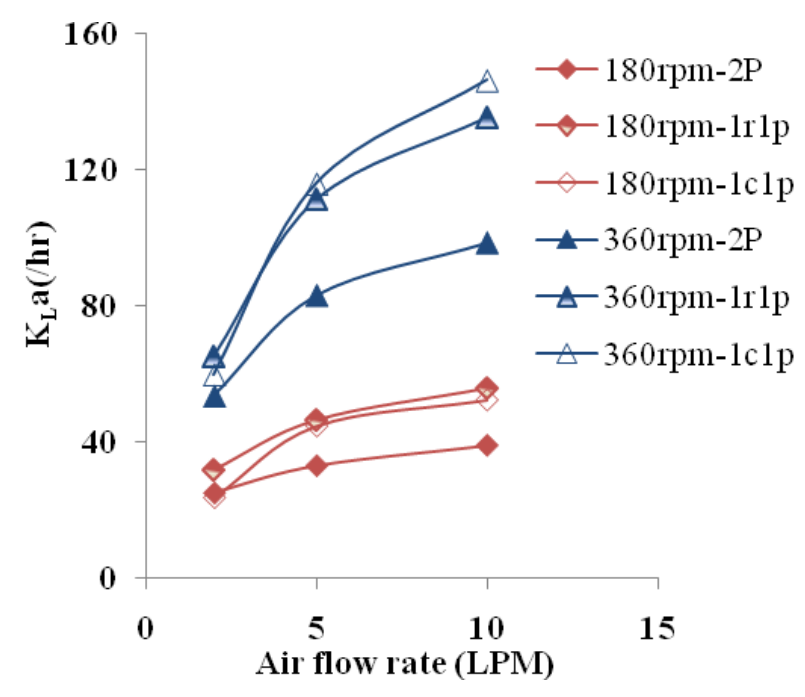

Fig-3: Effect of gassing rate on $\mathrm{K}_{\mathrm{L}}$ a for different Impeller combination

\subsection{Effect of Test Solutions on $\mathrm{K}_{\mathrm{L}} \mathrm{a}$}

Salts and Sugars reduce Bubble coalescence [2].Fig 4 shows the effect of the test fluids on $\mathrm{K}_{\mathrm{L}} \mathrm{a}$.Deionised water showed lesser $\mathrm{K}_{\mathrm{L}} \mathrm{a}$ values than Sodium Chloride and Dextrose solution at all aeration and agitation rates. However as shown in Figure 4 trials with $1 \%$ Sodium chloride resulted in higher $\mathrm{K}_{\mathrm{L}} \mathrm{a}$ values than $0.6 \%$ dextrose solution. At $5 \mathrm{lpm} \mathrm{K}_{\mathrm{L}} \mathrm{a}$ values leaped at $270 \mathrm{rpm}$ and then remained almost neutral at $360 \mathrm{rpm}$. But this leap was not seen at 10lpm-270rpm, where the results were similar to that at 5lpm. Higher flowrates of gas sparging results in coalescence of gas bubbles increasing the interfacial area for mass transfer.The observation made in present study of improved $\mathrm{K}_{\mathrm{L}}$ a values at 5lpm suggest that gas coalescing is aptly inhibited in the salt solution and thereafter the coalescing nature of high gassing overtakes the inhibition property of salts at $101 \mathrm{pm}$.

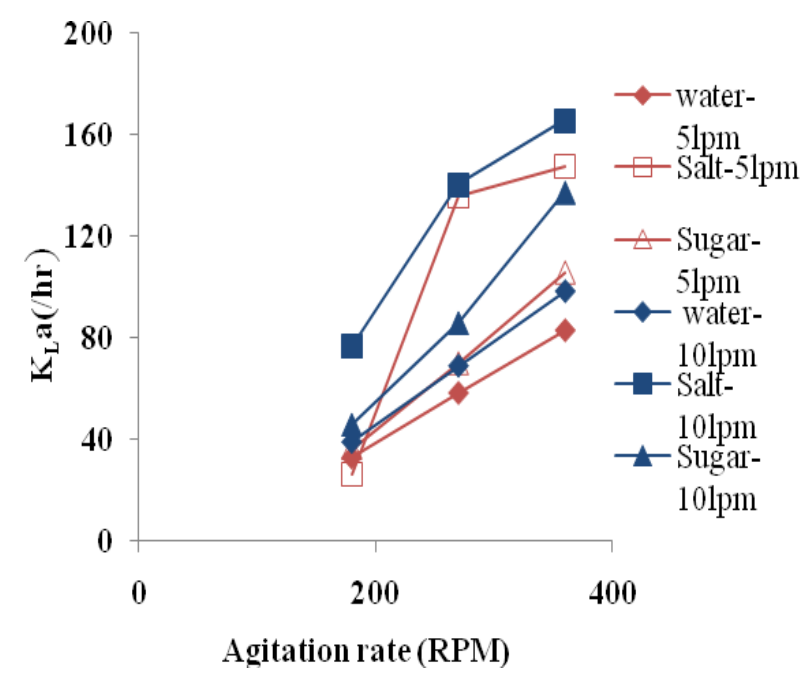

Fig-4: Effect of test solutions on $\mathrm{K}_{\mathrm{L}} \mathrm{a}$ for dual pitched blade Impeller combination

\subsection{Effect of Radial-Axial Impeller Combination on}

$\mathbf{K}_{\mathrm{L}} \mathbf{a}$

Figure 5 shows the effect of tested impeller combinations on the mass transfer coefficient at 5lpm and 10lpm for the test solution water.

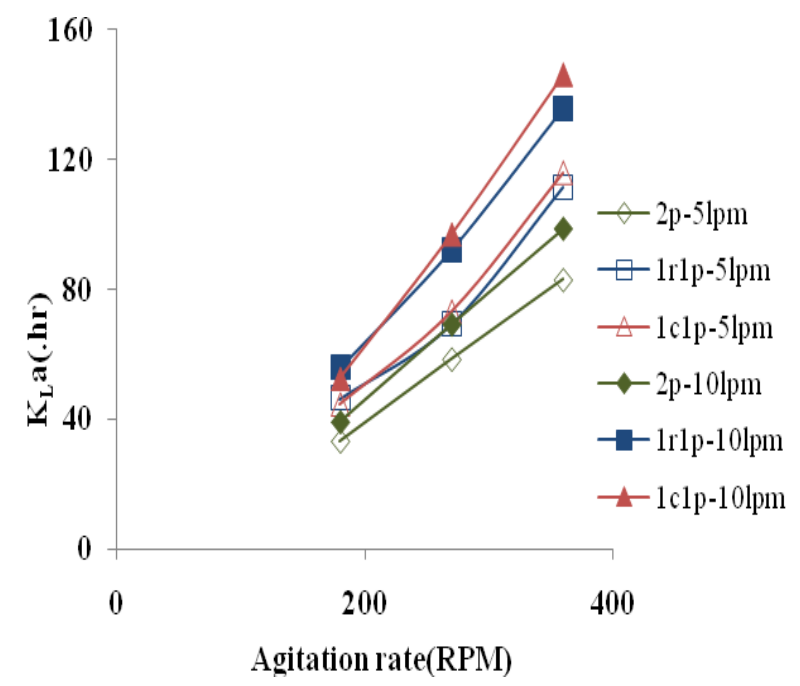

Fig-5: Effect of Impeller combination on $\mathrm{K}_{\mathrm{L}} \mathrm{a}$.

Studies performed with dual down pumping axial blade impeller showed markedly lesser mass transfer coefficient than radial-axial impeller combinations. Replacing the lower axial impeller with radial impeller - Rushton or curved blade impeller showed improved $\mathrm{K}_{\mathrm{L}}$ a values. This is because the radial impellers help in the bubble breakage as they emerge from sparger.1r1p and $1 \mathrm{c} 1 \mathrm{p}$ impeller combination yielded similar $\mathrm{K}_{\mathrm{L}} \mathrm{a}$ values at $5 \mathrm{lpm}$ and lower agitation speeds and only improved slightly at $10 \mathrm{lpm}$ and higher agitation rates. However since curved blade impeller requires lesser power than Rushton, using curved blade-pitched blade combination would be a better option.

\section{CONCLUSION}

Dual Impeller configuration with two Axial (Pitched blade), lower radial (Rushton and Curved) and Upper axial (Pitched blade) were studied and compared for the mass transfer capabilities in terms of mass transfer coefficient. The studies were performed at the conditions similar to Biochemical processes involving cells, choosing the aeration and agitation to match those used in Bioprocess Industry. At lower agitation and aeration rates Rushton-Pitched blade combination gave higher values of $\mathrm{K}_{\mathrm{L}} \mathrm{a}$. But as the aeration and agitation increased curved blade as lower disperser showed better results. Thus replacing the lower axial impeller with lower power number curved blade impeller can give improved results as it requires lesser power and imparts lesser shear than Rushton Turbine. This proves efficient in terms of maximizing the mass transfer with minimal power. Existing systems with Rushton-Pitched blade combination can be retrofitted with Curved blade. 


\section{REFERENCES}

[1]. Beth H. Junker, Zorina Mann, George Hunt., Retrofit of CD-6 (Smith) Impeller in Fermentation Vessels, ,2000 Applied Biochemistry and Biotechnology,89, 83-97.

[2]. Christine L. Henry and Vincent S. J. Craig, Inhibition of Bubble Coalescence by Osmolytes: Sucrose, Other Sugars, and Urea, Langmuir, 2009, 25(19), 11406-11412.

[3]. K.J.Myers, E.E. Janz, J.B. Fasano,Gas Dispersion capabilities of the CD-6 Impeller, 2006, 12th European Conference on Mixing, Bologna.

[4]. Carbon Monoxide Mass Transfer for Syngas Fermentation in a Stirred Tank Reactor with Dual Impeller Configurations, Andrew J. Ungerman, Theodore J. Heinde, Biotechnology Progress, 2007, 23(3), 613-620.

[5]. Meenal S. Puthli, Virendra K. Rathod, Aniruddha B. Pandit, Gas-liquid mass transfer studies with triple impeller system on a laboratory scale bioreactor, Biochemical Engineering Journal, 2005, 23(1), 25-30.

[6]. Fujasova, M, Linek, V Moucha, T, Mass transfer correlations for multiple-impeller gas-liquid contactors. Analysis of the effect of axial dispersion in gas and liquid phases on "local" $k(L) a$ values measured by the dynamic pressure method in individual stages of the vessel, 2007, Chemical Engineering Science, 62(6), 1650-1669.

[7]. S.J. Arjunwadkar, K. Sarvanan, P.R. Kulkarni, A.B. Pandit, Gas-liquid mass transfer in dual impeller bioreactor, Biochemical Engineering Journal, 1998,1(2), 99-106.

[8]. Aziz. A.R., Nik Sulaiman. N.M.,Shaliza Ibrahim, Mass Transfer Studies study on Various Curved Blade Impeller designs for Gas-Liquid Solid Systems,2004,Journalof Industrial Technology,13(1), 69-78.

[9]. Reza Afshar Ghoti, A.R. Abdul Aziz, Shaliza Ibrahim, Saeid Braoutian ,Arash Arami Nivya, Study of Various curved blade impeller geometries on power consumption in stirred vessel using response surface methodology, 2013 ,Journal of the Taiwan Institute of Chemical Engineers,44, 192-201.

\section{BIOGRAPHIES}

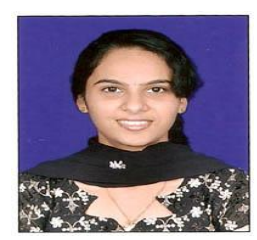

Ms. Shwetha Karanth obtained her Bachelor degree in Biotechnology. She is currently pursuing her Masters in Chemical Engineering at Dayananda Sagar College of Engineering, Bangalore. Her research interests include Fermentation and Bioprocess and Enzyme Technology.Email-karanth.shwetha31@yahoo.co.in

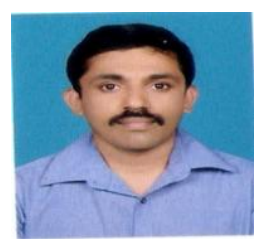

Mr. B.S. Thirumalesh is currently working as an Assistant Professor in the Department of Chemical Engineering, Dayananda Sagar College of Engineering, and Bangalore.His Research interest include Energy Integration, Mass Integration and Adsorption studies.Emailthirumaleshbs@yahoo.com 